\title{
Quantitative proteomic analysis of mouse testis uncovers cellular pathways associated with bisphenol A (BPA)-induced male infertility
}

\author{
Jian Jia ${ }^{1, *}$, Hang Xu${ }^{1, *}$, Changbo Chen ${ }^{1}$, Xiaoqian Zhang ${ }^{2}$, Xuexue Zhang ${ }^{3}$, Wei $\mathrm{Li}^{4}$ and Jing $\mathrm{Ma}^{1}$ \\ ${ }^{1}$ Department of Traditional Chinese Medicine, Xijing Hospital, The Fourth Military Medical University, Xian, Shaanxi, \\ China \\ ${ }^{2}$ College of Basic Medicine, Shaanxi University of Chinese Medicine, Xianyang, Shaanxi, China \\ ${ }^{3}$ First College of Clinical Medicine, Shaanxi University of Chinese Medicine, Xianyang, Shaanxi, China \\ ${ }^{4}$ Department of Histology and Embryology, The Fourth Military Medical University, Xian, Shaanxi, China
}

\begin{abstract}
Quantitative proteomic analysis was performed using iTRAQ to explore the potential regulation of differentially expressed proteins (DEPs) by bisphenol A (BPA) in murine testis. BPA was intraperitoneally injected into mice at a dose of $100 \mathrm{mg} / \mathrm{kg}$ body weight for 7 consecutive days. After BPA treatment, the histopathology changes of testis were examined. The circulating levels of testosterone $(\mathrm{T})$ and estradiol $\left(\mathrm{E}_{2}\right)$ were determined. iTRAQ was used to assess the expression levels of DEPs and to reveal potential interactions between different DEPs. Results showed that BPA caused histological damage in testicular tissues. The levels of $T$ and $E_{2}$ were affected by BPA exposure. The abundances of orosomucoid 1 (Orm1), haptoglobin (Hp), and insulin-like 3 (Insl3) were significantly lower in BPA-treated mice than those in control mice. The expression changes in the above-mentioned proteins were further validated at the protein level using Western blot analysis. We concluded that BPA affects histological morphology of testis and sex hormone productions. The regulation of key proteins (such as Orm1, Hp and Insl3) may reflect that these proteins may serve as important factors in male reproductive disorders caused by BPA, and these proteins are probably biomarkers for infertility caused by endocrine disrupting chemicals.
\end{abstract}

Key words: Bisphenol A - Testis - Infertility - Proteomics - Isobaric tags for relative and absolute quantitation

\section{Introduction}

Infertility has been recognized as a public health issue by WHO (Boivin et al. 2007) due to male reproductive dysfunction in approximately $50 \%$ of the affected couples (Anawalt 2013). Endocrine-disrupting chemicals (EDCs)

\footnotetext{
* These authors equally participated in this manuscript. Correspondence to: Jing Ma, Department of Traditional Chinese Medicine, Xijing Hospital, The Fourth Military Medical University, No.169 West Changle Road, Xincheng District, Xi'an, Shaanxi 710032, China

E-mail: jingma@fmmu.edu.cn

Wei Li, Department of Histology and Embryology, The Fourth Military Medical University, No.169 West Changle Road, Xincheng District, Xian, Shaanxi 710032, China

E-mail: liweipepeyato@163.com
}

have estrogenic effects, and may account for the increase in male reproductive disorders (Sharpe and Skakkebaek 1993). These EDCs are found in various materials such as additives, plastic products, building materials, personal care products and so on. Exposure to EDCs, even at low levels, leads to abnormality in health, including male and female reproductive disorders, breast development and cancer, prostate cancer, neuroendocrine issues, thyroid problems, metabolism and obesity, and cardiovascular endocrine issues (Gore et al. 2015). EDCs may contribute to male reproductive dysfunction by interfering with spermatogenesis, a process that is highly dependent on sex hormones (Dohle et al. 2003; Sweeney et al. 2015; WHO and UNEP, 2013).

Bisphenol A (BPA), namely 2,2-bis (4-hydroxyphenyl) propane, is one of the highest volume of EDCs produced worldwide (Dohle et al. 2003; Sweeney et al. 2015; WHO and UNEP, 2013). It is frequently used to produce plas- 
tics that serves as line food or drink containers, goods of common use, thermal receipts, and medical devices such as dental sealants (Chianese et al. 2018). It is well known that BPA can be detected in many human tissues, such as serum, urine, sweat, milk and placenta (Chianese et al. 2018). In general, the daily safe intake of BPA in human should be less than $1 \mu \mathrm{g} / \mathrm{kg}$ per day (Kang et al. 2006). The estrogenic and/or anti-androgenic properties of the chemically stable compound can impair testosterone production during male development, and therefore influence prostate and testis function in addition to spermatogenesis (Yeung et al. 2011). BPA induces disruption in meiotic progression during spermatogenesis (Liu et al. 2013), causes reduction in chromosome crossover (Vrooman et al. 2015), augments oxidative stress and apoptosis in mouse testis (Kaur et al. 2018). It is reported that exposure to xenoestrogens such as BPA could increase genital-tract abnormalities and increase incidence of infertility in Europe and the U.S. during the last 50 years (Vandenberg et al. 2007; Calafat et al. 2008). The BPA detection is associated with a higher level of circulating estradiol and a lower level of testosterone (Lan et al. 2017). The decreased sexual function in men is linked to the exposure to BPA in a dose-dependent manner (Rochester 2013). Futhermore, BPA is toxic to Leydig cells (LCs), especially on proliferation and motility (Chen et al. 2016), as well as testosterone production (Gonçalves et al. 2018). BPA causes damage to testicular tissue both in vivo and in vitro.

The technology of isobaric tags for relative and absolute quantitation (iTRAQ) has been applied to numerous experiments with the feature of measuring eight samples at one experiment with high precision. Nowadays, it is widely used in quantitative proteomics and has achieved good results. However, the current proteomics researches in male infertility are based on serum and spermatogenic cells, and few studies have been conducted on the proteomics of testis tissues of male infertility using iTRAQ technique.

In this study we employed iTRAQ technique to explore the potential regulation of proteins by BPA in testicular tissues of infertile men. The aim was to evaluate the action of BPA on testis tissues and explore the mechanism of infertility caused by EDCs.

\section{Materials and Methods}

\section{Animals and treatments}

Sixteen 6-week-old Kunming male mice $(20 \pm 3$ g) were obtained from the Experimental Animal Center of the Fourth Military Medical University (Xian, China). All the experimental protocols have been approved by the Ethics Committee for Animal Experimentation of the Fourth Military Medical University and in compliance with the National Institutes of
Health (NIH) Guide for the Care and Use of Laboratory Animals. They were housed in air-conditioned animal quarters in a constant 12 -hour light/dark cycle at $25 \pm 2^{\circ} \mathrm{C}$ temperature and $50 \pm 10 \%$ air humidity, with free access to food and water. BPA (CAS number 80-05-7, $\geq 99 \%$ ) was purchased from Sigma-Aldrich and the dose was chosen according to previous reports (Li et al. 2014; Tomza-Marciniak et al. 2018; Zhang et al. 2013). It was dissolved in corn oil (CAS number 8001-30-7, Sigma, MO, USA) and stored at $4^{\circ} \mathrm{C}$. The mice were randomly divided into Control group and treatment group ( $n=8$ /group). The mice in treatment group were injected intraperitoneally with BPA at $100 \mathrm{mg} / \mathrm{kg}$ body weight for 7 consecutive days (BPA group). In contrast, mice in Control group were injected intraperitoneally with corn oil at the same equal volume. After treatment, the mice were sacrificed to collect testis tissues and serum. To evaluate pathology, the left testis tissues were fixed with $4 \%$ paraformaldehyde overnight and then were subjected to routine hematoxylin and eosin (H\&E) staining. The right testis tissues were stored at $-80^{\circ} \mathrm{C}$ immediately after collection. The ophthalmic artery blood was immediately collected, and was centrifuged for serum preparation at 2,000 $\times g$ for $15 \mathrm{~min}$ to assess the serum levels of sex hormones.

\section{Morphological examination}

Upon harvest, testes were immediately fixed in $4 \%$ polyformaldehyde overnight at room temperature. Paraffinembedded testes tissue samples were generated and then cut into 5- $\mu$ m-thick sections. These sections were then stained with $\mathrm{H} \& \mathrm{E}$, and were observed under a light microscope (Carl Zeiss, ImagerM1, DE) at $200 \times$ and $400 \times$ magnification.

\section{Enzyme-linked immunosorbent assay (ELISA)}

Two ELISA kits (Cloud-Clone Corp, TX, USA) were used to determine the levels of testosterone (T, CEA458Ge) and estradiol ( $\left.\mathrm{E}_{2}, \mathrm{CEA} 461 \mathrm{Ge}\right)$, as per the manufacturer's instructions. After reconstitute the standard with standard diluent, samples and standards were added into 96-well strip plate. Once reagents were added, the plate was incubated for $30 \mathrm{~min}$ at $37^{\circ} \mathrm{C}$. The results were assessed on a microplate absorbance reader (Tecan sunrise, Austria) at $450 \mathrm{~nm}$ measurement. Average the duplicate readings for each standard, control and samples. Create a standard curve with the log of concentration on the $y$-axis and absorbance on the $\mathrm{x}$-axis. Based on this standard curve, the data were calculated. All tests were repeated three times.

\section{Proteome sample preparation and LC-MS/MS analysis}

Lysis buffer (8 M Urea, $40 \mathrm{mM}$ Tris-HCl or TEAB with $1 \mathrm{mM}$ PMSF, 2 mM EDTA and 10 mM DTT, pH 8.5) was used to 
extract proteins of 16 testis tissues. After centrifugation with $25,000 \times g$ at $4^{\circ} \mathrm{C}$ for $20 \mathrm{~min}$, the supernatant was transferred into a new tube, reduced with $10 \mathrm{mM}$ dithiothreitol (DTT) at $56^{\circ} \mathrm{C}$ for $60 \mathrm{~min}$, alkylated by $55 \mathrm{mM}$ iodoacetamide (IAM) in the dark at room temperature for $45 \mathrm{~min}$, and quantified by Bradford after centrifugation $\left(25,000 \times g, 4^{\circ} \mathrm{C}, 20 \mathrm{~min}\right)$. After Bradford assay, $30 \mu \mathrm{g}$ proteins were mixed with loading buffer in a centrifuge tube and heated at $95^{\circ} \mathrm{C}$ for $5 \mathrm{~min}$. Subsequently, the supernatant with proteins was centrifuged at $25000 \times g$ for $5 \mathrm{~min}$ and loaded to sample holes in $12 \%$ polyacrylamide gel with the running of SDS-PAGE in constant voltage at $120 \mathrm{~V}$ for $120 \mathrm{~min}$. Once it was finished, the gel was stained with Coomassie Blue for $120 \mathrm{~min}$, added destaining solution (40\% ethanol and $10 \%$ acetic acid ), and put on a shaker with an exchange of destaining solution for 3 5 times, 30 min each time. The gel lanes were then cut into multiple bands based on molecular weight and protein abundance in the specific region. Each gel band was digested with Trypsin Gold (Promega, Madison, WI, USA) before LC-MS/MS analysis (liquid chromotography linked with tandem mass spectrometry). After peptide labeling and fractionation, each fraction was resuspended in loading buffer ( $2 \%$ acetonitrile, $0.1 \%$ formic acid) and centrifuged at $20,000 \times g$ for $10 \mathrm{~min}$. The supernatant was loaded on UHPLC (UltiMate 3000, Thermo Scientific, USA) equipped with a trap and an analytical column. The peptides separated from nanoHPLC were subjected into the tandem mass spectrometry Q Exactive HF X (Thermo Fisher Scientific, San Jose, CA) for data-dependent acquisition (DDA) detection by nano-electrospray ionization. The parameters for MS analysis are as follows: electrospray voltage, $2.0 \mathrm{kV}$; precursor scan range, $350-1500 \mathrm{~m} / \mathrm{z}$ at a resolution of 60,000 in Orbitrap; MS/MS fragment scan range, $>100 \mathrm{~m} / \mathrm{z}$ at a resolution of 15,000 in HCD mode; normalized collision energy setting, 30\%; dynamic exclusion time, $30 \mathrm{~s}$; automatic gain control (AGC) for full MS target and MS2 target, $3 \mathrm{e} 6$ and 1e5, respectively; number of MS/MS scans following one MS scan, 20 most abundant precursor ions above a threshold ion count of 10,000 .

\section{MS/MS data analysis}

The raw MS/MS data were converted into MGF format through a thermo scientific tool Proteome Discoverer, and the exported MGF files were searched through Mas$\cot (\mathrm{v} 2.3 .02)$ in this project against the selected database (Uniprot-Mus musculus). The labeled peptides with isobaric tags were quantitatively analyzed by IQuant, a tool which combines multiple search engine results based on isobaric tags (Wen et al. 2014). The false discovery rate (FDR) at $1 \%$ was estimated by Picked protein FDR strategy to control the rate of false-positive at protein level after protein inference (protein-level FDR $\leq$ 0.01) (Savitski et al. 2015).

\section{Bioinformatic analysis}

We explored the functions of DEPs through Gene Ontology (GO) database (https://www.ebi.ac.uk/ols/ontologies/go) based on Uniprot database (https://www.uniprot.org/). Kyoto Encyclopedia of Genes and Genomes (KEGG, http://www. kegg.jp/) was used to study the relationships among different pathways. STRING (https://string-db.org/) was performed to link DEPs in protein-protein interactions (PPI) to illustrate the interaction of DEPs.

\section{Western blotting}

Testicular issues were stored at $-80^{\circ} \mathrm{C}$ before operation. After total proteins were extracted by RIPA Lysis Buffer (P0013B, Beyotime, China), protein concentrations were determined by Pierce BCA Protein Assay Kit (Thermo Fisher Scientific, MA, USA). $30 \mu \mathrm{g}$ of samples were separated by $10 \%$ SDS/PAGE and transferred to PVDF (polyvinylidene fluoride) membranes (Merck Millipore, Taunton, MA, USA). The membranes were then blocked with 5\% skim milk dissolved in TBS-T for $2 \mathrm{~h}$, and then incubated with primary antibodies overnight at $4^{\circ} \mathrm{C}$ : anti-Insl3 (1:1000, Abcam, Cambrige, UK), anti-Hp (1:1000, Proteintech, CA, USA), anti-Orm1 (1:1000, Proteintech, CA, USA) and antiGAPDH (1:1000, St John's Laboratory, CA, USA). Then, the blots were incubated with a peroxidase-conjugated secondary antibody (SA-10011, BioCytoSci, TX, USA) at room temperature for $2 \mathrm{~h}$, and were visualized with ECLPlus reagent (IC-5009, BioCytoSci, TX, USA). The optical density of the target band was analyzed by Image Pro Plus software (6.0, Media Cybernetics, MD).

\section{Statistical analysis}

Data were analyzed by one-way analysis of variance (ANOVA) using SPSS (version19.0, IBM, USA) and Prism softwares (version7.00, GraphPad, CA, USA), and were presented as mean \pm S.D. Significant differences between means were determined using Duncan and Tukey's honestly significant difference test; $p<0.05$ was considered as significant.

\section{Results}

\section{Histology changes}

The histopathological image/observation of testis tissues is shown in Figure 1. Figure 1A and C showed the normal development and morphology of testes in control mice, the structure of seminiferous tubules was normal and the spermatogenic cells were tightly connected and organized. In BPA group (Fig. 1B and D), however, the mount of Leydig 


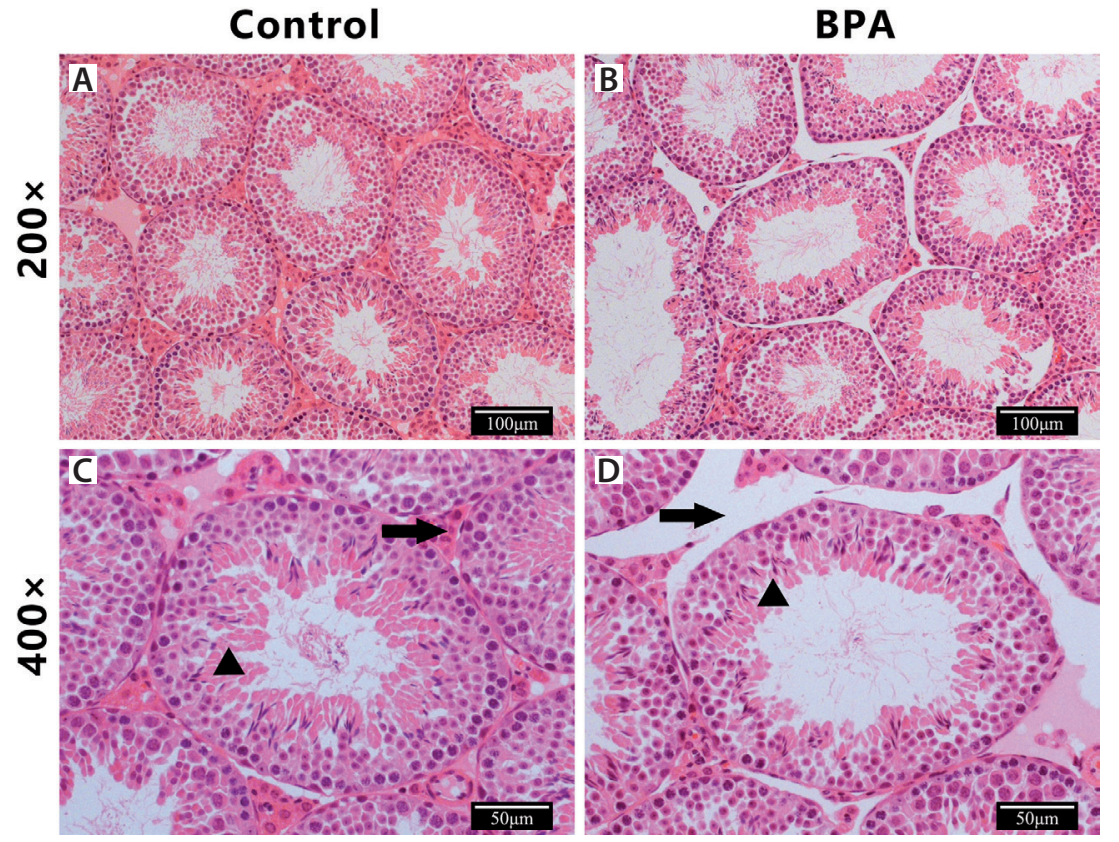

Figure 1. Histopathological changes of testis tissues: Control group $(\mathbf{A}, \mathbf{C})$ and BPA group $(\mathbf{B}, \mathbf{D})$. Arrow head refers to enlarged glandular cavity and decreased Leydig cells. Triangle refers to the distribution of sperm cells. Magnification $\times 200(A, B) ; \times 400(C, D)$. cells decreased and most seminiferous tubules contained less spermatogenic cells. The glandular cavity in BPA group was slightly enlarged and increased compared to that in Control group. The morphology of Leydig and spermatogenetic cells was abnormal. The layers of sperm cells were reduced, the array of sperm cells was disturbed, and the seminiferous tubules exhibited shrinkage and vacuolation.

\section{Effects of the sex hormone secretion by BPA}

Figure 2 showed the effects of the hormone secretion on the serums of mice using ELISA Kits. The testosterone level was slightly decreased in the BPA group but there was no significant difference between two groups (Fig. 2A). However, the estradiol level was significantly enhanced after BPA treatment (Fig. 2B), with the significant decrease of sex hormone ratio $\left(\mathrm{T} / \mathrm{E}_{2}\right)$ in BPA group (Fig. $2 \mathrm{C}$ ). BPA affected hormone secretion and disrupted the homeostasis of sex hormones in testis. Compared to androgen, BPA demonstrated more obvious effect on the estrogen production.

\section{Identification of DEPs after BPA treatment}

Totally 931866 spectrums were generated, 20728 peptides and 5192 proteins were identified with 1\% FDR. Among them 101 were up-regulated and 86 were down-regulated with foldChange $>1.2$ while 10 were up-regulated and 9 were down-regulated with foldChange $>1.5$. Table 1 shows DEPs in BPA group with foldChange $>1.5$ compared with Control group.

\section{GO and pathway analyses of DEPs}

Gene Ontology (GO) is consisted of three parts, including cellular component, molecular function and biological process. Figure 3A showed the results of GO enrichment analysis between BPA and Control groups. GO is a major bioinformatics initiative to unify the representation of gene and gene product attributes across all species. GO enrichment analysis showed the GO terms in which the DEPs were enriched in all candidate proteins, which represents
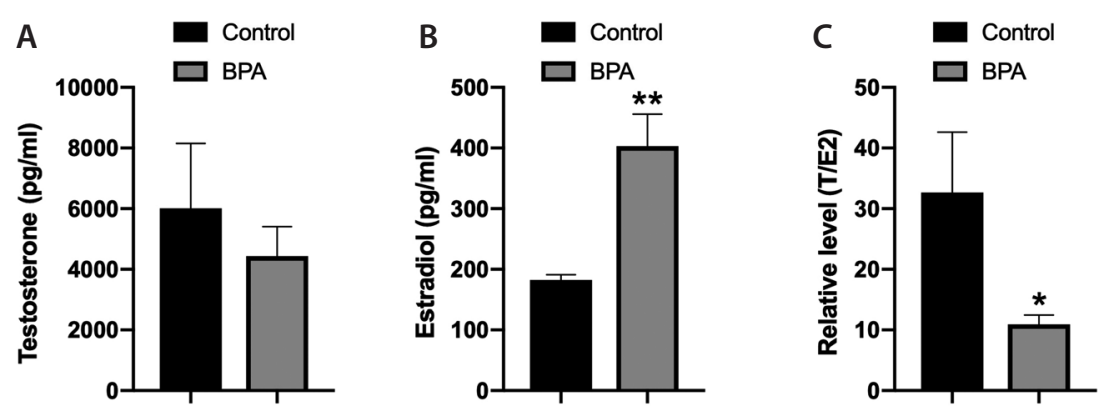

Figure 2. Effects of BPA treatment on sex hormone secretion levels. A. Testosterone production in serum $(p>0.05)$. B. Estradiol production in serum. C. The relative ratio of sex hormone $\left(\mathrm{T} / \mathrm{E}_{2}\right) .{ }^{*} p<0.05,{ }^{* *} p<0.001$ compared with the Control group. BPA, bisphenol A. T, testosterone. $\mathrm{E}_{2}$, estradiol. 
Table 1. DEPs in BPA group compared with Control group (FoldChange $>1.5$ or $<0.67$ )

\begin{tabular}{llcr}
\hline Protein ID & Protein & $\begin{array}{c}\text { Fold- } \\
\text { Change }\end{array}$ & $\begin{array}{r}p \text { value } \\
\left(\times 10^{-5}\right)\end{array}$ \\
\hline Up-regulated & & & \\
\hline sp|P98203|ARVC_MOUSE & Arvcf & 2.40 & 2.98 \\
sp|O55137|ACOT1_MOUSE & Acot1 & 1.78 & 0.104 \\
sp|Q3TCJ8|CCD69_MOUSE & Ccdc69 & 1.77 & 348.7 \\
sp|P61148|FGF1_MOUSE & Fgf1 & 1.70 & 147 \\
sp|P12710|FABPL_MOUSE & Fabp1 & 1.69 & 36.8 \\
sp|Q8BQZ4|RLGPB_MOUSE & Ralgapb & 1.59 & 2471 \\
sp|Q7TPM3|TRI17_MOUSE & Trim17 & 1.57 & 53.28 \\
sp|Q80U22|RUSC2_MOUSE & Rusc2 & 1.56 & 1098 \\
sp|Q5NCY3|CB5D1_MOUSE & Cyb5d1 & 1.55 & 429.1 \\
sp|Q5ND34|WDR81_MOUSE & Wdr81 & 1.50 & 345.5 \\
\hline Down-regulated & & & \\
\hline sp|Q8VIM9|IRGQ_MOUSE & Irgq & 0.48 & 38.77 \\
sp|Q8BND4|INT6L_MOUSE & Ints61 & 0.52 & 0.0913 \\
sp|Q5XG69|F169A_MOUSE & Fam169a & 0.52 & 40.35 \\
sp|P33622|APOC3_MOUSE & Apoc3 & 0.53 & 0.683 \\
sp|P02088|HBB1_MOUSE & Hbb-bt & 0.62 & 75.99 \\
sp|Q9QZ85|IIGP1_MOUSE & Iigp1 & 0.63 & 25.16 \\
sp|Q60590|A1AG1_MOUSE & Orm1 & 0.64 & 0.00514 \\
sp|Q61646|HPT_MOUSE & Hp & 0.65 & 100.4 \\
sp|Q6Q2Z6|ACOT5_MOUSE & Acot5 & 0.65 & 891.5 \\
\hline FoldChange,the fold values & f DEPs & & \\
\hline
\end{tabular}

FoldChange, the fold values of DEPs in BPA group compared with Control group; DEPs, differentially expressed proteins; BPA, bisphenol A.

the important or typical biology functions in the current study. "Reproduction" term in biological process was useful to explore DEPs of infertility caused by BPA. Thus, Table 2 demonstrated the DEPs of reproduction term.

KEGG pathway is a collection of manually drawn pathway maps representing our knowledge on the molecular interaction and reaction networks. Proteins usually interact with each other to play roles in certain biological functions. Figure 3B showed the effect of pathway enrichment analysis of DEPs based on KEGG database. The main pathways $(p<0.05)$ included ribosome, complement and coagulation cascades, malaria, antigen processing and presentation, leishmaniasis, ribosome biogenesis in eukaryotes, biosynthesis of unsaturated fatty acids, African trypanosomiasis, fatty acid elongation, Th1 and Th2 cell differentiation, inflammatory bowel disease, and systemic lupus erythematosus.

\section{PPI of the DEPs}

STRING (https://string-db.org/) is a database of known and predicted PPI. PPI is constructed to show the interaction of DEPs between the two groups (Fig. 4), the foldChange was more than 1.2 in Figure $4 \mathrm{~A}$ when it was more than 1.5 in Figure $4 \mathrm{~B}$. The minimum required interaction score was 0.4 (medium confidence) and the disconnected proteins in the network were hidden. In Figure 4B, 19 proteins were assigned to this network, among which 7 were identified as node proteins, including Fabp1, Apoc3, Hp, Orm1, Hbb-bt, Acot1, Acot5.

\section{Validation of the proteins highly related to reproduction}

We selected three proteins to verify the accuracy of proteomic analysis. Haptoglobin (Hp) and orosomucoid 1 (Orm1) were chosen from PPI because both of them are nodes. Insulin-like 3 (Insl3) was highly expressed in testis tissues rather than other tissues, and it was obviously expressed in reproduction term of GO analysis. These three proteins are very likely to be involved in reproduction process. Western blot was conducted to verify these three DEPs (Fig. 5). The levels of Insl3, Orm1 and Hp were decreased in the BPA group compared with Control group. The data were consistent with iTRAQ analysis, suggesting that our Proteomic data were reliable.

\section{Discussion}

With the rapid development of industry and economy, the deterioration of environment results in a large number of

Table 2. DEPs of GO reproduction term

\begin{tabular}{llcr}
\hline Protein ID & Protein & $\begin{array}{c}\text { Fold- } \\
\text { Change }\end{array}$ & $\begin{array}{r}p \text { value } \\
\left(\times 10^{-5}\right)\end{array}$ \\
\hline Up-regulated & & & \\
\hline sp|Q8C4X1|CENPX_MOUSE & Cenpx & 1.23 & 1722 \\
sp|P58742|AAAS_MOUSE & Aaas & 1.24 & 218.9 \\
sp|P49891|ST1E1_MOUSE & Sult1e1 & 1.38 & 5.62 \\
sp|Q8BWP5|TTPA_MOUSE & Ttpa & 1.32 & 39.07 \\
sp|O55047|TLK2_MOUSE & Tlk2 & 1.41 & 1.06 \\
sp|Q8BMD2|DZIP1_MOUSE & Dzip1 & 1.35 & 2.5 \\
sp|Q8VCB1|NDC1_MOUSE & Ndc1 & 1.24 & 99.52 \\
sp|P35235|PTN11_MOUSE & Ptpn11 & 1.22 & 23.04 \\
sp|Q9Z0E1|M1AP_MOUSE & M1ap & 1.28 & 10.76 \\
sp|P42232|STA5B_MOUSE & Stat5b & 1.26 & 306.4 \\
sp|Q5F2C3|MEIKN_MOUSE & Meikin & 1.26 & 341.5 \\
\hline Down-regulated & & & \\
\hline sp|Q9JKL5|CHP3_MOUSE & Tesc & 0.83 & 203.7 \\
sp|Q8CJI4|H1FNT_MOUSE & H1fnt & 0.80 & 432.4 \\
sp|O09107|INSL3_MOUSE & Insl3 & 0.79 & 339.4 \\
sp|Q61646|HPT_MOUSE & Hp & 0.65 & 100.4 \\
\hline
\end{tabular}

FoldChange, the fold values of DEPs in BPA group compared with Control group; DEPs, differentially expressed proteins; BPA, bisphenol A; GO, Gene Ontology database. 
A
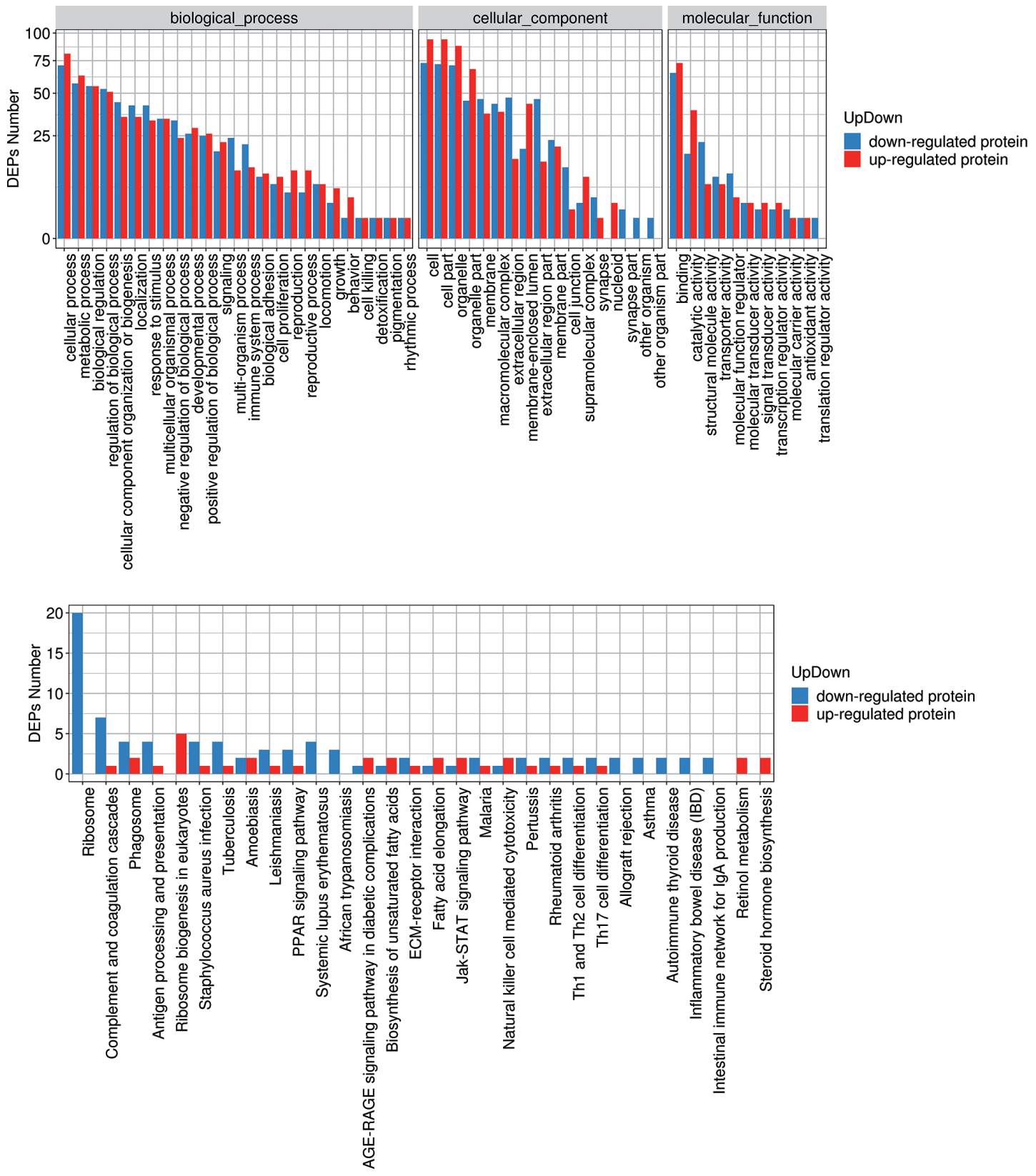

Figure 3. Gene Ontology (GO) enrichment (A) and Pathway enrichment (B) analysis for BPA vs. Control group. X-axis displays GO or pathway terms, and y-axis displays protein count. Red column, up-regulated proteins; blue column, down-regulated proteins. (See online version for color figure).

reproductive health problems, including the sexual precocity. More people are concerned about the effects of environmental hormones on human body. EDCs are related to xenoestrogens, antiestrogens, antiandrogens, disruption of thyroid function, disruption of corticoid function and other metabolic effects (Vidaeff and Sever 2005; De Coster and van Larebeke 2012). They exist everywhere in our daily life, and we can not avoid them. BPA, as one of classic EDCs, impairs the functions of testicular cells in men as well as reduces sperm counts in a rodent model and a human epidemiology study (Richter et al. 2007; Meeker et al. 2010).

Previous studies have focused on the proteomics of semen and Leydig cells (Chen et al. 2016; Rahman et al. 2018), while our research focuses on the whole testis tissue. The results from protein screening analyses have shown that many proteins are involved in reproductive health. We 
A

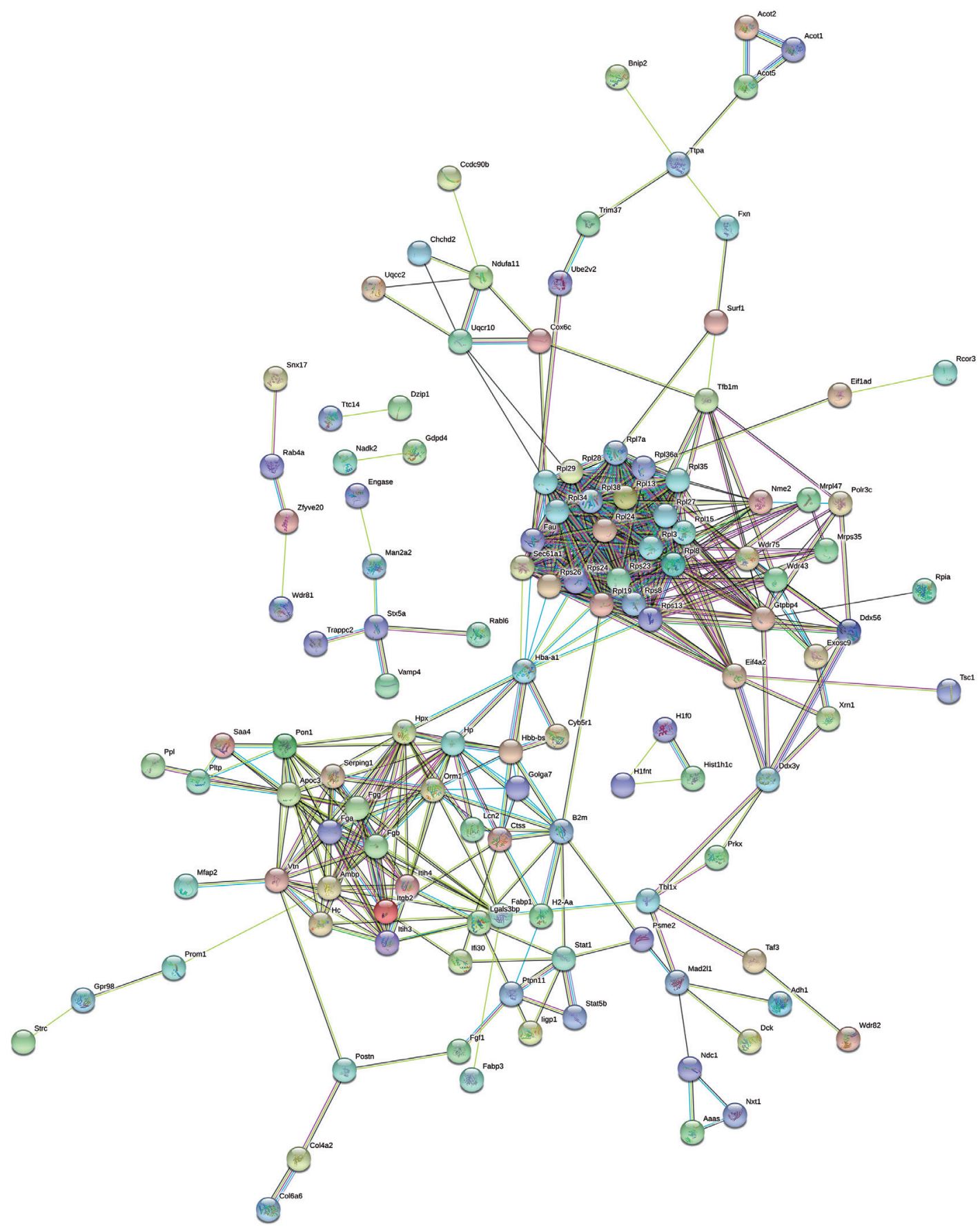

B

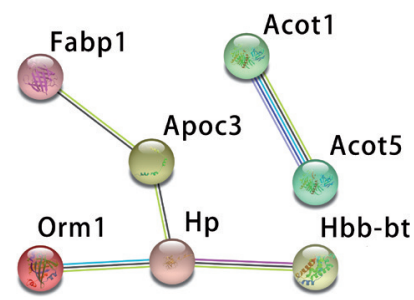

Figure 4. Protein-protein interaction (PPI) of DEPs for BPA vs. Control group. A. PPI when foldChange $>1.2$. B. PPI when foldChange $>1.5$. Seven proteins were assigned to this network, including Hp, Orm1, Hbb-bt, Apoc3, Fabp1, Acot 1 and Acot5. DEPs, differentially expressed proteins. 
A

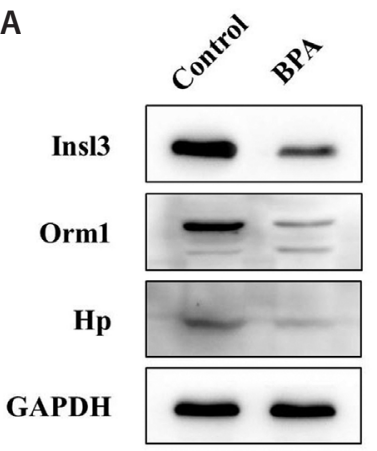

C

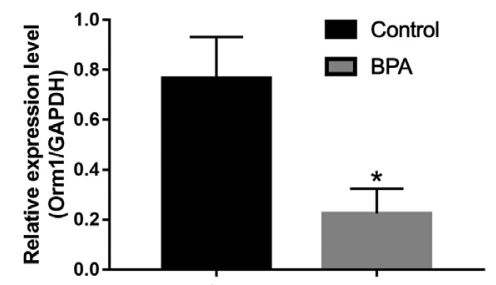

B

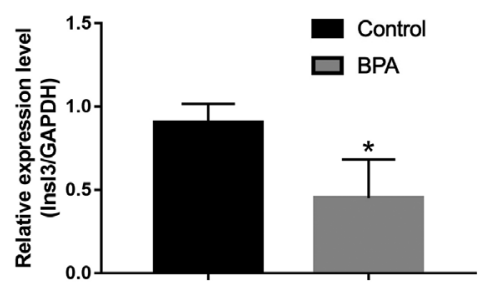

D

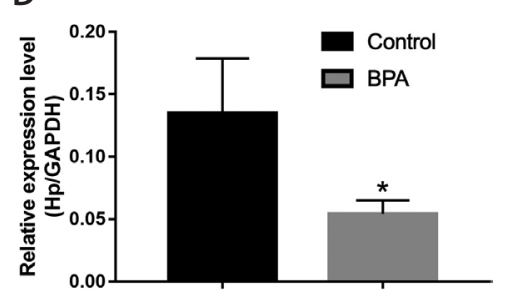

Figure 5. Validation of proteins related to reproduction. Protein expression level was detected by Western blotting (A). GAPDH was used as the internal loading control. The results shown below the gel indicated the quantification results normalized against the internal control. The protein expression of Insl3 (B), Orm1 (C) and $\mathrm{Hp}(\mathbf{D}) .{ }^{*} p<0.05$ compared with the Control group. BPA, bisphenol A. chose three distinct proteins for validation because they were selected from the PPI nodes and GO enrichment. The result shows that their expression levels are significantly changed. In recent studies, the reproductive effects of BPA were mainly reflected on cytotoxic effect, apoptosis ( $\mathrm{Li}$ et al. 2009; Qian et al. 2014), cell viability and follicle growth inhibition. Consistently in our study, histopathological observation of testis demonstrates that BPA significantly decreased spermatogenic cells in seminiferous tubules and large vacuolization could be observed within seminiferous tubules. Furthermore, the production of sex hormone secretion is affected by BPA. GO and Pathway enrichments show different aspects of DEPs function, especially reproductionrelated process. PPI was helpful to find protein nodes which are worth studying.

Three potential proteins were selected based on aforementioned bioinformatic analysis. Hp, as a Sertoli and germ cell product in testes, adds a new member to the growing family of metal transporters in the testis that are likely to play important roles in iron metabolism in the testis (O'Bryan et al. 1997). It is reported that Hp phenotype affects maternal fertility, and the effects of smoke on fertility depends on the Hp phenotype (Bottini et al. 2002). Additionally, women with mechanical factor infertility were more likely ( $p=0.042$ ) to have the Hp 1-1/2-1 phenotypes than the Hp2-2 phenotype (Weiss et al. 2013). HP has been implicated in reproductive function through its effect on inflammation, the immune system, and angiogenesis making it a protein of great interest to reproductive biologists (Bottini et al. 1999; Ueda et al. 2001). Hp $\alpha$ and $\beta$ peptides as well as Hp proteins have been identified in the follicular fluid aspirated during in vitro fertilization (IVF) (Angelucci et al. 2006; Schweigert et al. 2006). Orosomucoid 1 (Orm 1 ), which is also called $\alpha$-1-acid glycoprotein (AGP), is one of the acute-phase proteins. It is mainly synthesized by the liver and then is secreted to almost the entire body. Many biological properties of Orm have already been discussed in the literatures including protective effect against neonatal sepsis, interaction with phospholipid membranes, histamine binding capacity, and inhibition of platelet aggregation, neutrophil chemotaxis, superoxide production, and lymphocyte proliferation (Kremer et al. 1988). In addition, Orm has a more meaningful role here: acting as an acute-phase reactant. High dose BPA injection induces systemic injury, which causes a drastic change in the hepatic production of many plasma proteins. In our study, Orm 1 was down-regulated probably because chronic hepatitis, liver cirrhosis, or acute liver failure happened. Furthermore, Orm has the ability to bind and carry numerous basic and neutral drugs (Paxton 1983), especially the neutral drug steroids (Ganguly et al. 1967). BPA is one of the EDCs and acts like estrogen (Milligan et al. 1998; Rubin 2011). Its extensive integration with Orm may have led to the down-regulation of Orm 1 . It is reported that Orm in the oviducts additively suppresses sperm phagocytosis by polymorphonuclear neutrophils, which indicates that locally produced Orm may be involved in protecting sperm from phagocytosis by polymorphonuclear neutrophils in the bovine oviduct (Liu et al. 2014). Insl3 was first discovered as a unique and testis-specific gene transcript sequence 
independently in pigs (Adham et al. 1993) and mice (Pusch et al. 1996), respectively. Insl3 was originally referred to as Ley-IL (Leydig-insulin-like) or RLF (Relaxin-like factor). It is a major secretory product of the testicular Leydig cells in fetus and adult men. In rodent models, reduction in fetal Insl3 expression is an early marker of the testicular dysgenesis syndrome. Insl3 is also involved in adult traits, such as spermatogenesis and bone metabolism, and its expression declines consistently with age in adult men (Ivell and Anand-Ivell 2009). Insl3 is a member of the insulin-like group of peptide hormones. The functions of Insl3 such as testicular descent, lactation, pregnancy and birth, all of which are specific to mammalian viviparity and internal fertilization, have caused these molecules to be termed 'neohormones' which consists of other peptides such as hCG and oxytocin belong (Anand-Ivell et al. 2013). Furthermore, the Insl3/Rxfp2 system plays an integral role in promoting the production of the essential steroid precursor androstenedione through stimulation of the enzyme 17 $\alpha$-hydroxylase (Ivell and Anand-Ivell 2018). It is reported that the significantly monotonic trends in semen volume, sperm concentration and motility were associated with increasing quartiles of Insl3 ( $p<0.001)$ (Chang et al. 2017). Additionally, Insl 3 correlated negatively with BPA is proved and providing indirect evidence for an impact of EDCs on fetal Leydig cell Insl3 production (Chevalier et al. 2015), and diethylhexyl phthalate (DEHP) also down-regulated Insl3 mRNA expression (Song et al. 2008). Estrogens, acting through the estrogen receptor a $(E R \alpha)$, have been shown to repress expression of the gene encoding Insl3, a small peptide produced by testicular Leydig cells that is essential for normal testis descent. Estradiol $\left(\mathrm{E}_{2}\right)$ could repress Insl3 mRNA levels in MA-10 cells, a Leydig cell line model (Lague and Tremblay 2009).

It is reported that BPA could affect histological morphology of testis and sex hormone productions ( $\mathrm{Li}$ et al. 2009; Nakamura et al. 2010; Ibrahim et al. 2016). The estrogenic and anti-androgenic properties of BPA can also decrease testosterone production and increase estradiol production in our study. This may be due to the effects of BPA on Leydig cells. Testicular tissue contains a variety of proteins. The dose of BPA up to $100 \mathrm{mg} / \mathrm{kg}$ for 1 week causes acute testicular injury, which leads to changes in multiple pathways. Our experiment is the first to study the proteomics of testis tissues and provides a basis for clinic treatment.

In conclusion, this study provided the first evidence that infertility of BPA-caused mice might be involved in acute stimulation, inflammation, immunoreaction and production and metabolism of hormones in the testes. These reactions often occur simultaneously. Hp, Orm1 and Insl3 could act as potential targets for the therapeutic consideration in male infertility caused by BPA.
Acknowledgments. This study was supported by National Natural Science Foundation of China (No. 81573851) and Shaanxi International Cooperation and Communication Program (2016kw-012).

Conflict of interest. The authors declare that there are no conflicts of interest.

\section{References}

Adham IM, Burkhardt E, Benahmed M, Engel W (1993): Cloning of a cDNA for a novel insulin-like peptide of the testicular Leydig cells. J. Biol. Chem. 268, 26668-26672

Anand-Ivell R, Dai Y, Ivell R (2013): Neohormones as biomarkers of reproductive health. Fertil. Steril. 99, 1153-1160

https://doi.org/10.1016/j.fertnstert.2012.12.023

Anawalt BD (2013): Approach to male infertility and induction of spermatogenesis. J. Clin. Endocrinol. Metab. 98, 3532-3542 https://doi.org/10.1210/jc.2012-2400

Angelucci S, Ciavardelli D, Di Giuseppe F, Eleuterio E, Sulpizio M, Tiboni GM, Giampietro F, Palumbo P, Di Ilio C (2006): Proteome analysis of human follicular fluid. Biochim. Biophys. Acta 1764, 1775-1785 https://doi.org/10.1016/j.bbapap.2006.09.001

Boivin J, Bunting L, Collins JA, Nygren KG (2007): International estimates of infertility prevalence and treatment-seeking: potential need and demand for infertility medical care. Hum. Reprod. 22, 1506-1512 https://doi.org/10.1093/humrep/dem046

Bottini N, Gimelfarb A, Gloria-Bottini F, La Torre M, Lucarelli P, Lucarini N (1999): Haptoglobin genotype and natural fertility in humans. Fertil. Steril. 72, 293-296 https://doi.org/10.1016/S0015-0282(99)00210-1

Bottini N, Magrini A, Macmurray J, Cosmi E, Nicotra M, GloriaBottini F, Bergamaschi A (2002): Smoking, haptoglobin and fertility in humans. Tob. Induc. Dis. 1, 3-6

https://doi.org/10.1186/1617-9625-1-1-3

Calafat AM, Ye X, Wong LY, Reidy JA, Needham LL (2008): Exposure of the U.S. population to bisphenol A and 4-tertiaryoctylphenol: 2003-2004. Environ. Health Perspect. 116, 39-44 https://doi.org/10.1289/ehp.10753

Chang WH, Wu MH, Pan HA, Guo PL, Lee CC (2017): Semen quality and insulin-like factor 3: Associations with urinary and seminal levels of phthalate metabolites in adult males. Chemosphere 173, 594-602 https://doi.org/10.1016/j.chemosphere.2017.01.056

Chen ZJ, Zhang KS, Ge LC, Liu H, Chen LK, Du J, Wang HS (2016): Signals involved in the effects of bisphenol A (BPA) on proliferation and motility of Leydig cells: a comparative proteomic analysis. Toxicol. Res. (Camb). 5, 1573-1584 https://doi.org/10.1039/C6TX00258G

Chevalier N, Brucker-Davis F, Lahlou N, Coquillard P, Pugeat M, Pacini P, Panaia-Ferrari P, Wagner-Mahler K, Fenichel P (2015): A negative correlation between insulin-like peptide 3 and bisphenol A in human cord blood suggests an effect of endocrine disruptors on testicular descent during fetal development. Hum. Reprod. 30, 447-453 
https://doi.org/10.1093/humrep/deu340

Chianese R, Viggiano A, Urbanek K, Cappetta D, Troisi J, Scafuro M, Guida M, Esposito G, Ciuffreda LP, Rossi F, et al. (2018): Chronic exposure to low dose of bisphenol A impacts on the first round of spermatogenesis via SIRT1 modulation. Sci. Rep. 8, 2961 https://doi.org/10.1038/s41598-018-21076-8

De Coster S, van Larebeke N (2012): Endocrine-disrupting chemicals: associated disorders and mechanisms of action. J. Environ. Public Health 2012, 713696 https://doi.org/10.1155/2012/713696

Dohle GR, Smit M, Weber RF (2003): Androgens and male fertility. World J. Urol. 21, 341-345 https://doi.org/10.1007/s00345-003-0365-9

Ganguly M, Carnighan RH, Westphal U (1967): Steroid-protein interactions. XIV. Interaction between human alpha 1-acid glycoprotein and progesterone. Biochemistry 6, 2803-2814 https://doi.org/10.1021/bi00861a022

Gonçalves GD, Semprebon SC, Biazi BI, Mantovani MS, Fernandes GSA (2018): Bisphenol A reduces testosterone production in TM3 Leydig cells independently of its effects on cell death and mitochondrial membrane potential. Reprod. Toxicol. 76, 26-34 https://doi.org/10.1016/j.reprotox.2017.12.002

Gore AC, Chappell VA, Fenton SE, Flaws JA, Nadal A, Prins GS, Toppari J, Zoeller RT (2015): Executive summary to EDC-2: the endocrine society's second scientific statement on endocrinedisrupting chemicals. Endocr. Rev. 36, 593-602 https://doi.org/10.1210/er.2015-1093

Ibrahim MA, Elbakry RH, Bayomy NA (2016): Effect of bisphenol A on morphology, apoptosis and proliferation in the resting mammary gland of the adult albino rat. Int. J. Exp. Pathol. 97, 27-36 https://doi.org/10.1111/iep.12164

Ivell R, Anand-Ivell R (2009): Biology of insulin-like factor 3 in human reproduction. Hum. Reprod. Update 15, 463-476 https://doi.org/10.1093/humupd/dmp011

Ivell R, Anand-Ivell R (2018): Insulin-like peptide 3 (INSL3) is a major regulator of female reproductive physiology. Hum. Reprod. Update. 24, 639-651 https://doi.org/10.1093/humupd/dmy029

Kang JH, Kondo F, Katayama Y (2006): Human exposure to bisphenol A. Toxicology 226, 79-89 https://doi.org/10.1016/j.tox.2006.06.009

Kaur S, Saluja M, Bansal MP (2018): Bisphenol A induced oxidative stress and apoptosis in mice testes: Modulation by selenium. Andrologia 50 https://doi.org/10.1111/and.12834

Kremer JM, Wilting J, Janssen LH (1988): Drug binding to human alpha-1-acid glycoprotein in health and disease. Pharmacol. Rev. 40, 1-47

Lague E, Tremblay JJ (2009): Estradiol represses insulin-like 3 expression and promoter activity in MA-10 Leydig cells. Toxicology 258, 101-105 https://doi.org/10.1016/j.tox.2009.01.013

Lan HC, Wu KY, Lin IW, Yang ZJ, Chang AA, Hu MC (2017): Bisphenol A disrupts steroidogenesis and induces a sex hormone imbalance through c-Jun phosphorylation in Leydig cells. Chemosphere 185, 237-246 https://doi.org/10.1016/j.chemosphere.2017.07.004
Li Y, Zhang W, Liu J, Wang W, Li H, Zhu J, Weng S, Xiao S, Wu T (2014): Prepubertal bisphenol A exposure interferes with ovarian follicle development and its relevant gene expression. Reprod. Toxicol. 44, 33-40 https://doi.org/10.1016/j.reprotox.2013.09.002

Li YJ, Song TB, Cai YY, Zhou JS, Song X, Zhao X, Wu XL (2009): Bisphenol A exposure induces apoptosis and upregulation of Fas/FasL and caspase- 3 expression in the testes of mice. Toxicol. Sci. 108, 427-436 https://doi.org/10.1093/toxsci/kfp024

Liu C, Duan W, Li R, Xu S, Zhang L, Chen C, He M, Lu Y, Wu H, Pi H, et al. (2013): Exposure to bisphenol A disrupts meiotic progression during spermatogenesis in adult rats through estrogen-like activity. Cell Death Dis. 4, e676 https://doi.org/10.1038/cddis.2013.203

Liu J, Marey MA, Kowsar R, Hambruch N, Shimizu T, Haneda S, Matsui M, Sasaki M, Hayakawa H, Pfarrer C, Miyamoto A (2014): An acute-phase protein as a regulator of sperm survival in the bovine oviduct: alpha 1-acid-glycoprotein impairs neutrophil phagocytosis of sperm in vitro. J. Reprod. Dev. 60, 342-348 https://doi.org/10.1262/jrd.2014-049

Meeker JD, Ehrlich S, Toth TL, Wright DL, Calafat AM, Trisini AT, Ye X, Hauser R (2010): Semen quality and sperm DNA damage in relation to urinary bisphenol A among men from an infertility clinic. Reprod. Toxicol. 30, 532-539 https://doi.org/10.1016/j.reprotox.2010.07.005

Milligan SR, Balasubramanian AV, Kalita JC (1998): Relative potency of xenobiotic estrogens in an acute in vivo mammalian assay. Environ. Health Perspect. 106, 23-26 https://doi.org/10.1289/ehp.9810623

Nakamura D, Yanagiba Y, Duan Z, Ito Y, Okamura A, Asaeda N, Tagawa Y, Li C, Taya K, Zhang SY, et al. (2010): Bisphenol A may cause testosterone reduction by adversely affecting both testis and pituitary systems similar to estradiol. Toxicol. Lett. 194, 16-25 https://doi.org/10.1016/j.toxlet.2010.02.002

O'Bryan MK, Grima J, Mruk D, Cheng CY (1997): Haptoglobin is a Sertoli cell product in the rat seminiferous epithelium: its purification and regulation. J. Androl. 18, 637-645

Paxton JW (1983): Alpha 1 -acid glycoprotein and binding of basic drugs. Methods Find Exp. Clin. Pharmacol. 5, 635-648

Pusch W, Balvers M, Ivell R (1996): Molecular cloning and expression of the relaxin-like factor from the mouse testis. Endocrinology 137, 3009-3013 https://doi.org/10.1210/endo.137.7.8770925

Qian W, Zhu J, Mao C, Liu J, Wang Y, Wang Q, Liu Y, Gao R, Xiao H, Wang J (2014): Involvement of CaM-CaMKII-ERK in bisphenol A-induced Sertoli cell apoptosis. Toxicology 324, 27-34 https://doi.org/10.1016/j.tox.2014.06.001

Rahman MS, Kwon WS, Ryu DY, Khatun A, Karmakar PC, Ryu BY, Pang MG (2018): Functional and proteomic alterations of F1 capacitated spermatozoa of adult mice following gestational exposure to bisphenol A. J. Proteome Res. 17, 524-535 https://doi.org/10.1021/acs.jproteome.7b00668

Richter CA, Birnbaum LS, Farabollini F, Newbold RR, Rubin BS, Talsness CE, Vandenbergh JG, Walser-Kuntz DR, Vom SF 
(2007): In vivo effects of bisphenol A in laboratory rodent studies. Reprod. Toxicol. 24, 199-224

https://doi.org/10.1016/j.reprotox.2007.06.004

Rochester JR (2013): Bisphenol A and human health: a review of the literature. Reprod. Toxicol. 42, 132-155

https://doi.org/10.1016/j.reprotox.2013.08.008

Rubin BS (2011): Bisphenol A: an endocrine disruptor with widespread exposure and multiple effects. J. Steroid Biochem. Mol. Biol. 127, 27-34 https://doi.org/10.1016/j.jsbmb.2011.05.002

Savitski MM, Wilhelm M, Hahne H, Kuster B, Bantscheff M (2015): A scalable approach for protein false discovery rate estimation in large proteomic data sets. Mol. Cell. Proteomics 14, 2394-2404 https://doi.org/10.1074/mcp.M114.046995

Schweigert FJ, Gericke B, Wolfram W, Kaisers U, Dudenhausen JW (2006): Peptide and protein profiles in serum and follicular fluid of women undergoing IVF. Hum. Reprod. 21, 2960-2968 https://doi.org/10.1093/humrep/del257

Sharpe RM, Skakkebaek NE (1993): Are oestrogens involved in falling sperm counts and disorders of the male reproductive tract? Lancet 341, 1392-1395 https://doi.org/10.1016/0140-6736(93)90953-E

Song XF, Wei GH, Liu X, Zhang DY, Chen X, Deng YJ (2008): Effects of diethylhexyl phthalate (DEHP) on INSL3 mRNA expression by Leydig cells derived from mouse embryos and in newborn mice. J. Int. Med. Res. 36, 512-521 https://doi.org/10.1177/147323000803600316

Sweeney MF, Hasan N, Soto AM, Sonnenschein C (2015): Environmental endocrine disruptors: Effects on the human male reproductive system. Rev. Endocr. Metab. Disord. 16, 341-357 https://doi.org/10.1007/s11154-016-9337-4

Tomza-Marciniak A, Stepkowska P, Kuba J, Pilarczyk B (2018): Effect of bisphenol A on reproductive processes: A review of in vitro, in vivo and epidemiological studies. J. Appl. Toxicol. 38, $51-80$ https://doi.org/10.1002/jat.3480

Ueda K, Yamamasu S, Nakamura Y, Honda K, Ozaki K, Fujino Y, Ishiko O, Ogita S (2001): Involvement of phenotypes and serum levels of haptoglobin in the outcome of in vitro fertilization and embryo transfer. Gynecol. Obstet Invest. 51, 219-222 https://doi.org/10.1159/000058053

Vandenberg LN, Hauser R, Marcus M, Olea N, Welshons WV (2007): Human exposure to bisphenol A (BPA). Reprod. Toxicol. 24, 139-177

https://doi.org/10.1016/j.reprotox.2007.07.010

Vidaeff AC, Sever LE (2005): In utero exposure to environmental estrogens and male reproductive health: a systematic review of biological and epidemiologic evidence. Reprod. Toxicol. 20, $5-20$ https://doi.org/10.1016/j.reprotox.2004.12.015

Vrooman LA, Oatley JM, Griswold JE, Hassold TJ, Hunt PA (2015): Estrogenic exposure alters the spermatogonial stem cells in the developing testis, permanently reducing crossover levels in the adult. PLoS Genet. 11, e1004949 https://doi.org/10.1371/journal.pgen.1004949

Weiss A, Ozeri D, Beck-Fruchter R, Lavee M, Geslevich Y, Levy AP (2013): Haptoglobin phenotypes and in vitro fertilization treatment outcomes. Syst. Biol. Reprod. Med. 59, 281-284 https://doi.org/10.3109/19396368.2013.794874

Wen B, Zhou R, Feng Q, Wang Q, Wang J, Liu S (2014): IQuant: an automated pipeline for quantitative proteomics based upon isobaric tags. Proteomics 14, 2280-2285 https://doi.org/10.1002/pmic.201300361

WHO, UNEP (2013): State of the science of endocrine disrupting chemicals - 2012. World Health Organization

Yeung BH, Wan HT, Law AY, Wong CK (2011): Endocrine disrupting chemicals: Multiple effects on testicular signaling and spermatogenesis. Spermatogenesis 1, 231-239 https://doi.org/10.4161/spmg.1.3.18019

Zhang C, Wang A, Sun X, Li X, Zhao X, Li S, Ma A (2013): Protective effects of lycium barbarum polysaccharides on testis spermatogenic injury induced by bisphenol A in mice. Evid. Based Complement. Alternat. Med. 2013, 690808 https://doi.org/10.1155/2013/690808

Received: December 20, 2019

Final version accepted: April 2, 2020 